\title{
Better long-term survival in young and middle-aged women than in men after a first myocardial infarction between 1985 and 2006. an analysis of 8630 patients in the Northern Sweden MONICA Study
}

Rose-Marie Isaksson ${ }^{1,2}$, Jan-Håkan Jansson ${ }^{3,6}$, Dan Lundblad ${ }^{4,6}$, Ulf Näslund ${ }^{5,6}$, Karin Zingmark ${ }^{7}$ and Mats Eliasson ${ }^{4,6^{*}}$

\begin{abstract}
Background: There is conflicting and only scant evidence on the effect of gender on long-term survival after a myocardial infarction (MI). Our aim was to analyse sex-specific survival of patients for up to 23 years after a first Ml in northern Sweden and to describe time trends.

Methods: The Northern Sweden MONICA Myocardial Infarction Registry was linked to The Swedish National Cause of Death Registry for a total of 8630 patients, 25 to 64 years of age, 6762 men and 1868 women, with a first Ml during 1985-2006. Also deaths before admission to hospital were included. Follow-up ended on August 30, 2008.

Results: Median follow-up was 7.1 years, maximum 23 years and the study included 70072 patient-years. During the follow-up $45.3 \%$ of the men and $43.7 \%$ of the women had died. Median survival for men was 187 months (95\% confidence interval (Cl) 179-194) and for women 200 months (95\% Cl 186-214). The hazard ratio (HR) for all cause mortality after adjustment for age group was $1.092(1.010-1.18, P=0.025)$ males compared to females, i.e. 9 percent higher survival in women. After excluding subjects who died before reaching hospital HR declined to $1.017(95 \% \mathrm{Cl} 0.93-1.11, P=0.7)$. For any duration of follow-up a higher proportion of women were alive, irrespective of age group. The 5-year survivals were $75.3 \%$ and $77.5 \%$, in younger $(<57$ years) men and women and were $65.5 \%$ and $66.3 \%$ in older (57-64 years) men and women, respectively. For each of four successive cohorts survival improved. Survival time was longer for women than for men in all age groups.

Conclusions: Age-adjusted survival was higher among women than men after a first $\mathrm{Ml}$ and has improved markedly and equally in both men and women over a 23-year period. This difference was due to lower risk for women to die before reaching hospital.
\end{abstract}

\section{Background}

Mortality from myocardial infarction (MI) in Sweden, as in most other developed countries, has decreased markedly during recent decades [1]. The international MONICA collaboration hypothesizes that the decline is mainly due to a decrease in the classical risk factors smoking, cholesterol and blood pressure [2], although recent modelling strongly emphasizes the pivotal role of

\footnotetext{
* Correspondence: mats.eliasson@nll.se

${ }^{4}$ Department of Medicine, Sunderby Hospital, Luleå, Sweden

Full list of author information is available at the end of the article
}

lower cholesterol [3]. However, MI still remains the most common cause of death in Sweden and other western regions [4]. Women are affected by MI later in life than men. Below 55 years of age the risk of MI in men is almost four times that of women [5]. With increasing age, the incidence of MI increases markedly, but the incidence and mortality from MI remain lower in women throughout life [5].

Most studies of long-term survival after an MI have had a follow-up time of maximum 5 years [6-10], only a few have had a longer period [11-14]. Furthermore, 
most have included both the first and recurrent MIs $[6,10,11,13,14]$. Only few studies have documented the impact of sex in long-term survival after an MI $[6,10,11,15]$. Two of these studies from the $1990 \mathrm{~s}$ $[6,10]$ included first and recurrent MIs, had a short perspective and found no sex differences in the 30-day to 1-year mortalities. A Scottish study of 201114 patients with a first MI during the years 1986-1995, covering also initial out-of-hospital deaths, showed that women did not fare worse than men when age was taken into account [15]. In an American study including 12331 patients with both first and recurrent MIs, with a 6-year follow-up, long-time survival was also similar between the sexes [11].

No studies have investigated sex-specific time trends in long-term mortality in patients with a first MI. As there are important sex differences in mortality before admission to hospital, men fare worse [15], such data must be included to give the true picture of the total mortality burden of ischemic heart disease (IHD). To our knowledge only one study has taken a specific sex and age approach when analysing trends in long-term survival after a first MI [12]. This recently presented Norwegian hospital-based study included 12000 patients, divided into two age groups $(<60$ years, $>60$ years) with a first MI. However, pre-hospital mortality was not included. A substantial decline in longterm mortality in both sex and age groups over 23 years was found but mortality did not differ between men and women.

The aim of this study was to analyse sex-specific longterm survival up to 23 years in patients below 65 years of age with a first MI during 1985-2006 in northern Sweden. In addition, we aimed to study if trends over time differed between sexes.

\section{Methods}

This study relies on two separate registries in Sweden: The Northern Sweden MONICA Myocardial Infarction Registry and The Swedish National Cause of Death Registry.

The WHO MONICA project (Monitoring Trends and Determinants in Cardiovascular Disease) started in the beginning of the $1980 \mathrm{~s}$. The Northern Sweden MONICA Study is ongoing in Västerbotten and Norrbotten counties since 1985. The Myocardial Infarction Registry includes cases based on the MONICA criteria [16].

The registry is population based, which means that all MI events are included, not only those who are admitted to hospital. Most importantly, all deaths out of hospital are evaluated for possible myocardial infarction. The case findings of possible events are based mainly on two sources, hospital discharge registries and death certificates. To validate the diagnosis of MI, medical history, clinical symptoms, ECG and cardiac enzymes are used based on strict WHO MONICA criteria throughout the period. MI diagnoses are based on typical symptoms and biomarkers for myocardial necrosis. If only one of these parameters is positive, ECG analysis is included for final diagnosis.

In fatal cases, information obtained from death certificates and necropsy reports, when available, is also included. In fatal events, possible infarction and unclassifiable infarctions are included, according to the international MONICA protocol. An event is considered first ever if the history according to the hospital records and the MONICA database is free from previous clinically recognized $\mathrm{MI}$, otherwise the event is considered as recurrent [16]. Since 2000 all the reporting hospitals have switched to the use of troponins, and the local reference values are applied.

During the study period from January 1, 1985 to December 31, 2006, a total of 12635 patients who fulfilled the MONICA criteria and diagnosed as a definite MI were registered in the MONICA myocardial infarction registry. In this study only first ever MIs in subjects 25-64 years of age were included. Hence, a total of 8630 patients were included. The population at-risk in the area was 258576 (December 31, 2009). Data on clinical characteristics were not routinely registered before 1989 .

All patients were followed up for information on vital status using The Swedish Cause of Death Registry until August 30, 2008. Patients not identified in the register were assumed to be alive at that date and censored. It is estimated that $93 \%$ of all deaths are reported to Statistics Sweden within 10 days and $100 \%$ within 30 days using the unique personal identification number (PIN) assigned to every citizen in Sweden [17]. The two registries (MONICA and The Cause of Death Registry) were linked by the PIN. The endpoint studied was death from any cause, i.e. all cause mortality.

\section{Ethical considerations}

The Northern Sweden MONICA Study was approved by the Research Ethics Committee of Umeå University, and the data handling procedures were approved by the National Computer Data Inspection Board. Participants or relatives to nonsurvivors gave written consent.

\section{Statistical analyses}

Separate groups according to age at onset were constructed to achieve groups of similar size: 25-50 years, 51-56 years, 57-60 years and 61-64 years for men and women. The patients were separated into four cohorts representing the year of onset of MI: 1985-1988, 19891994, 1995-2000 and 2001-2006. Survival time was calculated as the number of days between the date of the MI and the date of death, or August 30, 2008. 
Survival times were computed with Kaplan-Meier product limit estimate. Hypothesis test of no difference in survival was calculated by Cox regression analysis, with adjustment for age group. For explanatory reasons we performed a sensitive analysis by omitting those who died out of hospital and repeated the survival analysis. All analyses were carried out using the statistical computer program PASWStatistics 18.

\section{Results}

A total of 8630 subjects, 6762 men and 1868 women, with a first MI between 1985 and 2006, were included. Mean age for men was 55.5 years and for women 56.4 years. Clinical characteristics are shown in Table 1. No data, except age, were available for the first period, and missing data ranged from 1 to $16 \%$. Age at onset was stable for men but declined slightly among women over time.

Previous known ischaemic heart disease (i.e. angina pectoris) was initially more common among men and then similar between the sexes. The prevalence of hypertension declined but was more common among women during the whole study period. Known diabetes was more common among women and increased somewhat over time. Regular smoking was much more common and increased among women, while it was stable in men. No data were available on the prevalence of hyperlipidaemia or treatment with lipid-lowering drugs.

Median follow-up was 85 months (7.1 years) and maximum 288 months (24 years). Total follow-up was 70 002 patient-years. During the follow-up a total of 3066 (45.3\%) of the men and $798(42.7 \%)$ of the women died. Among men 959 (14.2\%) died before admission to hospital and among women 205 (11.0\%). Mean age for those who died before reaching hospital was 56.0 years for men and 57.1 years for women.

\section{Survival according to sex}

In a Cox regression analysis the hazard ratio (HR) for all-cause mortality, after adjustment for age group, was 1.09 (95\%CI 1.010-1.18, $P=0.025)$ males vs. females, i.e. 9 percent higher survival in women than in men. An analysis using age and year of onset as time-dependent variables gave the same results (data not shown). After excluding subjects who died before reaching hospital HR declined to 1.017 (95\%CI 0.93-1.11, $P=0.7$ ).

Median survival for men was 187 months (95\% CI 179194) and for women 200 months (CI 186-214) (Figure 1). In Table 2 the proportions that were alive at 7 days, 28 days, 1, 3, 5, 10 and 20 years after their MI are presented, stratified for age. For any duration of follow-up a higher proportion of women were alive, irrespective of age group. As the median follow up was 7.1 years figures on 5-year survival will include most subjects. Five years after a first MI $75.3 \%$ and $77.5 \%$, among younger $(<57$ years $)$ men and women were alive, and $65.5 \%$ and $66.3 \%$ in older (57-64 years) men and women were alive, respectively. After excluding subjects who died before reaching hospital median survival for men was 225 months (95\% CI 217-233) and for women 222 months (95\% CI 207-236).

\section{Survival according to age group}

In each age group women had a longer median survival than men (Table 3, Figure 2). Survival was shorter with higher age.

\section{Survival according to cohort}

For each cohort survival increased (Figure 3). During the first and third periods survival in women exceeded that of men, while the reverse was true for the second period, and no difference was seen during the last period (Table 1, Figure 4).

Table 1 Clinical characteristics at baseline of men and women with a first myocardial infarction during four consecutive time periods, 1985 to $2006^{*}$

\begin{tabular}{|c|c|c|c|c|c|c|}
\hline & & 1985-1988 & 1989-1994 & $1995-2000$ & 2001-2006 & 1985-2006 \\
\hline \multirow[t]{7}{*}{ Men } & $N$ & 1463 & 1927 & 1711 & 1662 & 6763 \\
\hline & Survived (\%) & $408(27.8)$ & $903(46.9)$ & 1092 (63.8) & $1296(78.0)$ & $3697(54.7)$ \\
\hline & Age $(\%)$ & 55.60 & 55.30 & 55.30 & 55.70 & 55.50 \\
\hline & IHD (\%) & & $355(30.1)$ & $520(31.3)$ & $412(25.3)$ & $1287(28.8)$ \\
\hline & Hypertension (\%) & & $782(42.6)$ & $531(33.4)$ & $598(36.9)$ & 1911 (37.9) \\
\hline & Diabetes (\%) & & $221(11.6)$ & $242(14.2)$ & $262(15.9)$ & $725(13.8)$ \\
\hline & Regular smoking (\%) & & $683(38.2)$ & $545(43.0)$ & $516(38.2)$ & $1744(39.6)$ \\
\hline \multirow[t]{6}{*}{ Women } & $N$ & 350 & 509 & 495 & 514 & 1868 \\
\hline & Survived (\%) & $101(28.9)$ & $230(45.2)$ & $338(68.3)$ & $401(78.0)$ & $1070(57.3)$ \\
\hline & Age & 57.10 & 56.50 & 55.90 & 56.20 & 56.40 \\
\hline & $\operatorname{IHD}(\%)$ & & $86(27.5)$ & $138(29.0)$ & $127(25.2)$ & $351(27.2)$ \\
\hline & Hypertension (\%) & & $247(50.9)$ & $196(42.4)$ & $231(47.2)$ & $674(46.9)$ \\
\hline & Diabetes (\%) & & $82(16.3)$ & $71(14.4)$ & $97(18.9)$ & $250(16.6)$ \\
\hline
\end{tabular}

\footnotetext{
${ }^{*}$ Missing data: IHD $15.5 \%$, hypertension $5 \%$, diabetes $0.6 \%$, smoker $16 \%$.
} 


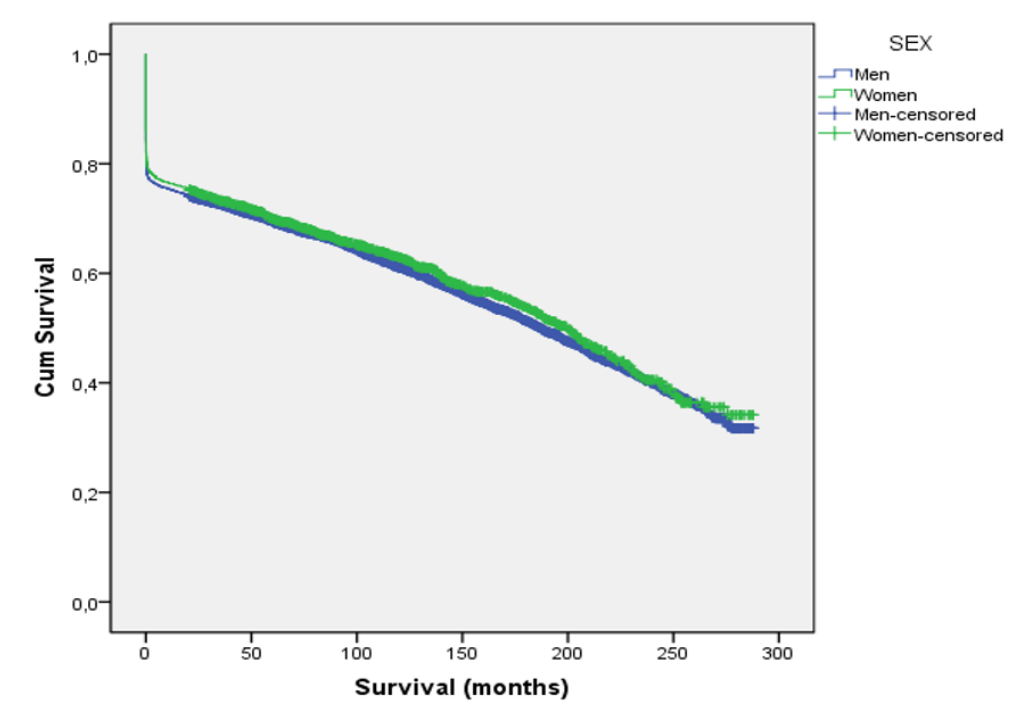

Figure 1 Median survival after a first myocardial infarction according to sex.

\section{Discussion}

Between 1985 and 2006 long-term survival after a first MI has increased in both men and women between 25 and 64 years of age in northern Sweden. Over the whole 23-year period women showed a nine percent higher survival than men. This difference was due to lower risk for women to die before reaching hospital, and during the last period similar rates of long time survival were noted in men and women.

During the last two decades differences in outcome between men and women suffering an MI have been increasingly highlighted. Still the evidence is conflicting regarding gender specific outcomes and prognosis after MI. Comparison between studies is complicated by methodological differences such as differences in data collection, registration methods, study population, case definition and research period. However, no study has previously presented data from such a large database as

Table 2 Proportion of men and women surviving after a first myocardial infarction stratified for age

\begin{tabular}{|c|c|c|c|c|}
\hline \multirow[b]{3}{*}{$\begin{array}{l}\text { Time after } \\
\text { Ml }\end{array}$} & \multicolumn{4}{|c|}{ Survival (\%) at different times after MI } \\
\hline & \multicolumn{2}{|c|}{ Men } & \multicolumn{2}{|c|}{ Women } \\
\hline & $\begin{array}{l}\text { Age 25-55 } \\
\text { years }\end{array}$ & $\begin{array}{l}\text { Age } 56-64 \\
\text { years }\end{array}$ & $\begin{array}{l}\text { Age 25-55 } \\
\text { years }\end{array}$ & $\begin{array}{l}\text { Age 56-64 } \\
\text { years }\end{array}$ \\
\hline 7 days & 82.2 & 77.6 & 85.2 & 79.1 \\
\hline 28 days & 81.2 & 74.9 & 82.9 & 76.9 \\
\hline 1 years & 79.2 & 72.3 & 81.4 & 73.5 \\
\hline 3 years & 77.3 & 68.9 & 79.3 & 69.9 \\
\hline 5 years & 75.3 & 65.5 & 77.5 & 66.3 \\
\hline 10 years & 71.0 & 58.0 & 75.1 & 59.8 \\
\hline 20 years & 63.9 & 48.9 & 69.7 & 51.2 \\
\hline
\end{tabular}

the Northern Sweden MONICA Study, over such a long time as 23 years, including exclusively patients with their first MI, and including also patients who died before reaching the hospital.

Improvement in long-term survival after a first MI is probably attributable to a combination of better treatment before admission to hospital by paramedics, improvements in the acute coronary care, and secondary prevention. Over the study period there was an increasing use of evidence-based medical treatments and coronary artery revascularisation at the onset of MI, all of which have been shown to reduce cardiac morbidity and mortality [18]. Secondary prevention programmes and

Table 3 Median survival in men and women after a first MI according to age group

\begin{tabular}{|c|c|c|}
\hline \multicolumn{3}{|c|}{ Survival (months) } \\
\hline Age at onset & Sex & Median \\
\hline \multirow[t]{2}{*}{$25-50$} & Men & 278 \\
\hline & Women & NA \\
\hline \multirow[t]{2}{*}{$51-56$} & Men & 217 \\
\hline & Women & 250 \\
\hline \multirow[t]{2}{*}{$57-60$} & Men & 177 \\
\hline & Women & 192 \\
\hline \multirow[t]{2}{*}{$61-64$} & Men & 115 \\
\hline & Women & 136 \\
\hline \multirow[t]{2}{*}{$25-64$} & Men & 187 \\
\hline & Women & 200 \\
\hline
\end{tabular}




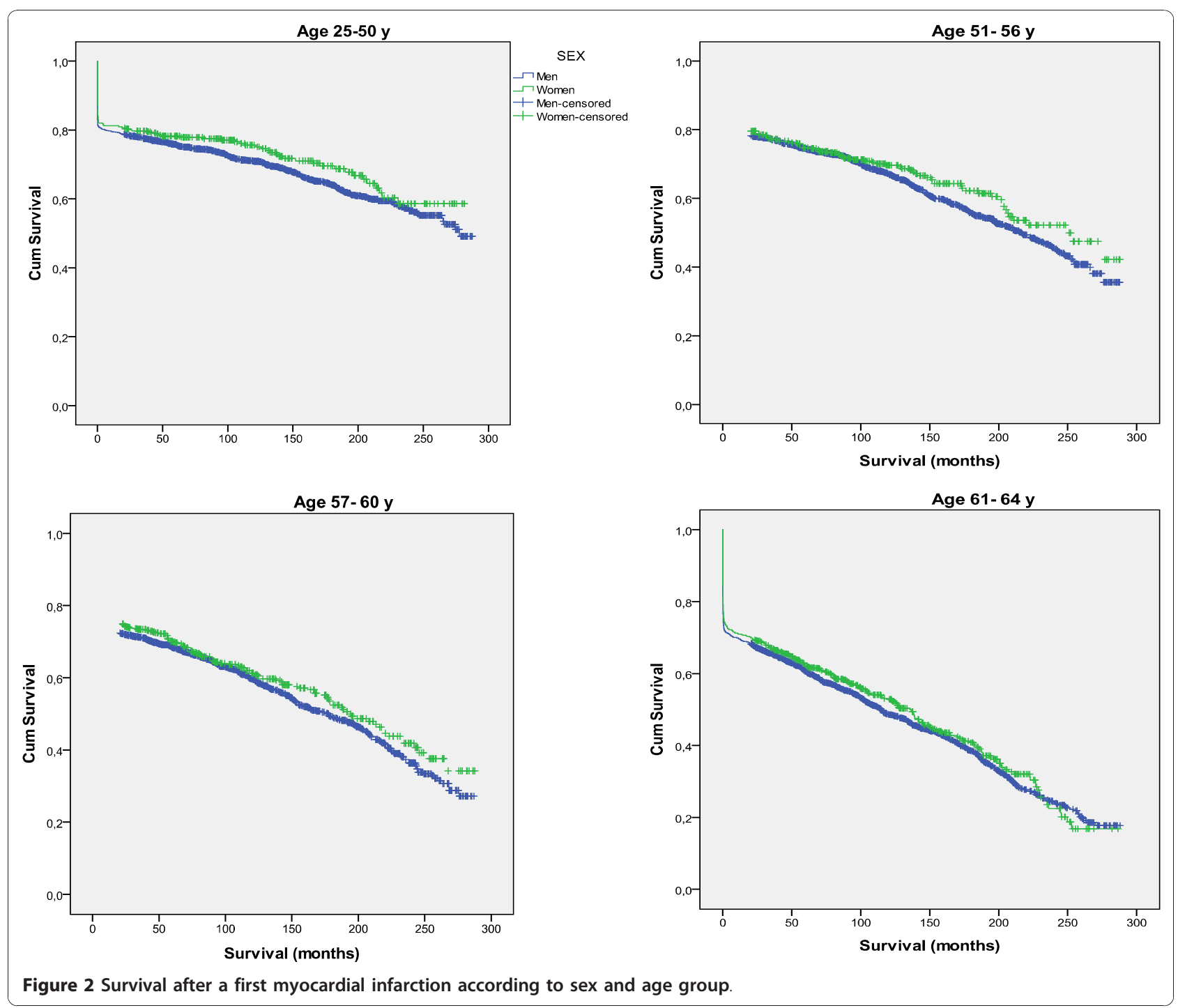

patient activities have become routine in the follow-up of MI patients in Sweden. Since the early nineties all patients have been called and invited for individual counselling by cardiologists or dedicated nurses, for educational programs and for exercise programs in groups. Prescriptions for platelet inhibitors, beta-blockers, ACE-inhibitors and statins have increased in parallel with evidence and publications of landmark studies [3]. The attendance rate at clinical follow-up after an MI in Sweden has been generally high, approximately $80-90 \%$, although patients with lower socioeconomic status have had a lower participation rate.

The increased long-term survival as shown in our study also reflects the forceful implementation of primary and secondary prevention of MI which has been shown in a recently published modelling study from Sweden [3]. Approximately $36 \%$ of the decrease in mortality in coronary heart disease during 1986-2002 was due to treatment of individuals and $55 \%$ was due to population risk factor reductions including total cholesterol, smoking and blood pressure levels. The substantial reduction in total cholesterol level explained almost $40 \%$ of the decrease, and almost $10 \%$ of the mortality reduction came from a decline in smoking prevalence.

Interestingly, during the studied 23-year period, the incidence of first MI before the age of 65 years in northern Sweden decreased among men but was unchanged among women [16]. In the Northern Sweden MONICA study we recently presented data on time trends in major cardiovascular risk factors from six population surveys covering the same population and time period as the MI registry. Significant improvements were observed in the control of hypertension, smoking, and an increased level of education between 1986 and 2009 noted [19]. In spite of increasing BMI no increase in the prevalence of diabetes was found. Total cholesterol 


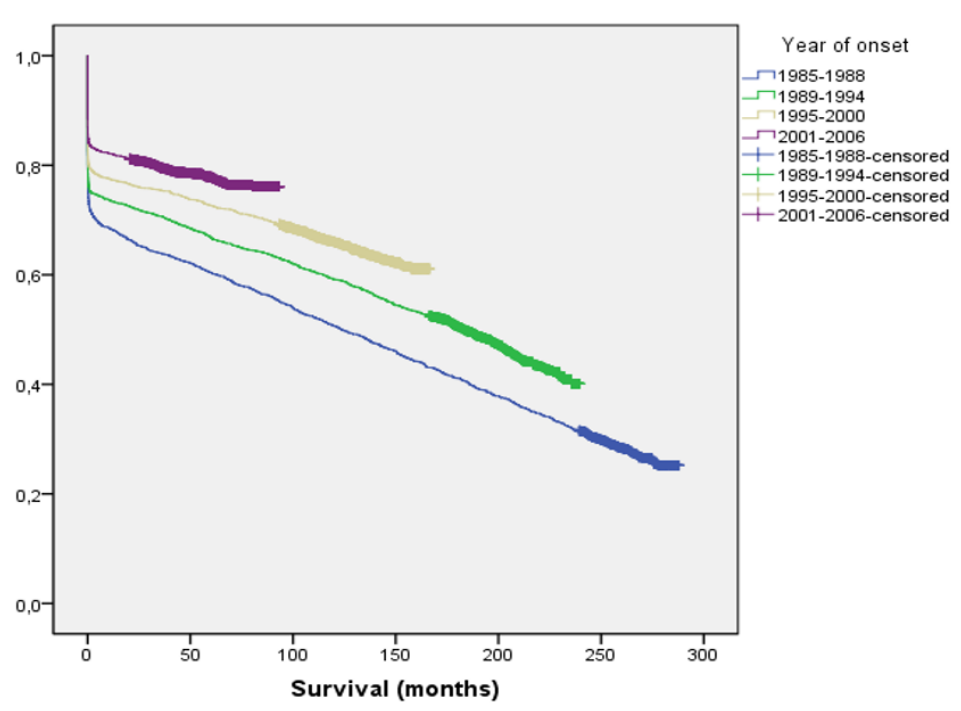

Figure 3 Survival after a first myocardial infarction according to year of onset.
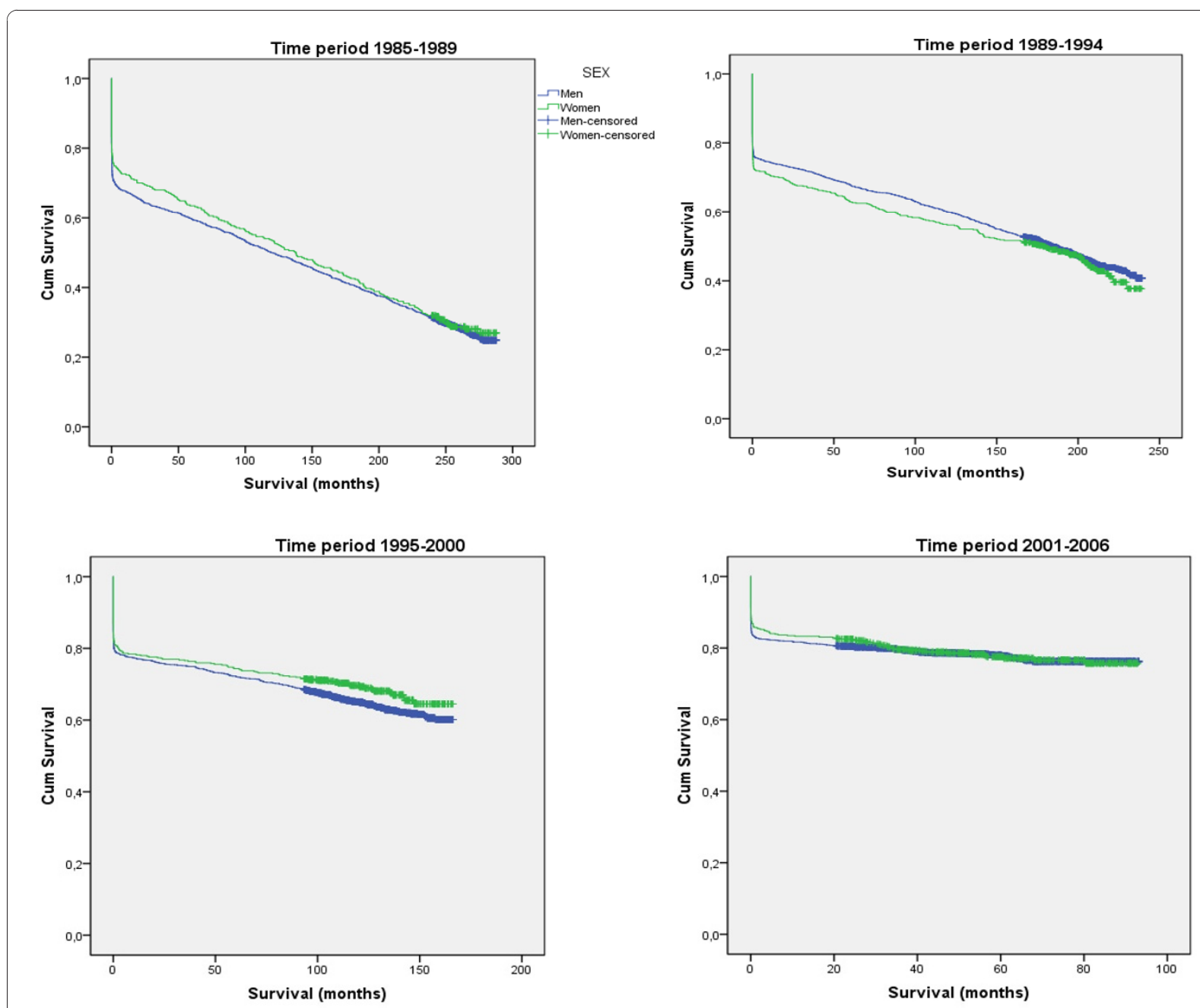

Figure 4 Survival after a first myocardial infarction according to sex and year of onset. 
levels decreased $0.9 \mathrm{mmol} / \mathrm{l}$ in both men and women, which is likely to have a major impact on the improved prognosis over time. Lower risk factor levels were achieved in both men and women although the decline in smoking was much slower in women. In 2009 more women than men were still regular smokers. This may be a factor behind our finding of no difference between men and women during our last observation period.

During the last two decades there has been an ongoing debate about the differences between men and women suffering from MI in terms of treatment and outcome $[20,21]$. It has been repeatedly stated that women with MI are treated less aggressively than men and that reperfusion therapy is under-utilized in women with MI [22]. Women are also said to be less likely to be referred for coronary angiography and revascularization procedures such as percutaneous coronary interventions and coronary artery bypass grafting [23]. However, one recent Swedish study with 1744 patients reported that men and women were treated similarly [24].

Our results do not support the contention that the outcome of a first MI in women is worse than in men. On the contrary, we found a slightly longer median survival and higher probability of being alive during longterm follow-up in accordance with recent large studies $[11,12,15]$. Excluding subjects dead before arrival to hospital abolished all gender differences but women still did not fare any worse than men. This was expected, as it was previously known that men had a higher proportion of out-of-hospital deaths. This has important implications for interpretation of studies based solely on those admitted to hospital in which an apparent worse prognosis for women has been evident. It also underscores the unique properties of the Northern Sweden MONICA registry mirroring the total mortality burden of a first MI in the society.

The reasons for the difference in long-term outcome between men and women are unclear but higher fatality in men before reaching of hospital surely contributes. Further explanations to a great extent are speculative. We had no data on severity of the MI which may be a link in the causal chain leading to somewhat better prognosis for women. Still, the sex-differences in this study underscore the importance of a gender perspective on all parts of the MI-journey, including symptom representation and recognition, reasons for delay, diagnosis, treatment and long-term outcome.

There is clear evidence that early treatment, especially within the first "golden hour" results in a considerable survival benefit [25]. There are conflicting data regarding whether there are gender differences in clinical manifestations and delay before seeking treatment for acute cardiac symptoms. However, in Northern Sweden we found no major gender differences in type of symptoms or time between onset and medical presence as defined in the WHO MONICA manual based on the same population as the present study [26].

\section{Strengths and limitations}

The major strengths of our study was the large number of patients studied over such a long period, 23 years, which is longer than most studies. When analysing mortality from MI it is not enough to analyse in-hospital mortality. A considerable proportion of deaths from MI occur outside hospital. We also included deaths before admission, thereby accurately describing the total burden of disease. The validity of our findings is strengthened by the strict and uniform use of the MONICA criteria over the whole period. It should also be noted that this is not a random sample from the population. The Northern Sweden MONICA registry includes all those who suffered an MI in the defined geographical area with no loss to follow-up.

The main limitation and a major drawback of this study is the upper age limit chosen in the WHO MONICA project. When the project was initiated in the early $1980 \mathrm{~s}$, the focus was on what was regarded as premature cardiovascular disease. Therefore, an upper age limit was set at 65 years. Thus, the results cannot be extrapolated to older age groups or to the total population.

Another limitation of the present study is the introduction of troponins (in the $1990 \mathrm{~s}$ ) as markers of myocardial injury. These markers were not included in the original MONICA criteria from the early eighties for validation and classification of events. This means that MI definitions before and after the year 2000 differ to some extent. It is complicated to handle this situation when all the hospitals in Sweden changed their diagnostic markers and stopped using the older biomarkers that were described in the MONICA project. Our analysis [16] suggests that this may be the reason for the attenuated decline in incidence of MI noted after 2000, but no impact was noted on casefatality (i.e. proportion dead after 28 days). The switch to troponins would not affect the large proportion of subjects dead before hospital, nor is it probable that the effect would be differential according to sex and thus invalidate our findings.

\section{Conclusions}

We conclude that over a 23-year period the age-adjusted survival after a first MI below the age of 65 years is higher among women than among men due to lower risk for women to die before reaching hospital. Survival is similar in those having an MI after 2000. For both men and women survival improved impressively. 


\section{Acknowledgements}

This work was supported by grants from Norrbotten and Västerbotten County Councils, the Heart Foundation of Northern Sweden, the Swedish Research Council (MFR), the Joint Committee of Northern Sweden Health Care Region (Visare Norr), the Heart and Chest Foundation, the Stroke fund King Gustaf V's and Queen Victoria's foundation, Vårdalsstiftelsen and the Social Sciences Research Council.

\section{Author details}

${ }^{1}$ The Northern Sweden MONICA Myocardial Registry, Department of Research, Norrbotten County Council, Luleå, Sweden. ${ }^{2}$ Department of Nursing, Umeå University, Umeå, Sweden. ${ }^{3}$ Department of Medicine and Geriatrics, Skellefteå Hospital, Skellefteå, Sweden. ${ }^{4}$ Department of Medicine, Sunderby Hospital, Luleå, Sweden. ${ }^{5}$ Department of Cardiology, Heart Centre, University Hospital, Umeå, Sweden. ${ }^{6}$ Department of Public Health and Clinical Medicine, Umeå University, Umeå, Sweden. 'Department of Research, Norrbotten County Council, Luleå, Sweden.

\section{Authors' contributions}

ME designed the study, analysed data and drafted the manuscript. RMI analysed data and drafted the manuscript. JHJ, DL, KZ and UN drafted and revised the manuscript and contributed to the analysis. DL is the principal investigator for the MONICA Registry. All authors have read and approved the final manuscript.

\section{Competing interests}

The authors declare that they have no competing interests.

Received: 3 September 2010 Accepted: 5 January 2011 Published: 5 January 2011

\section{References}

1. Kesteloot H, Sans S, Kromhout D: Dynamics of cardiovascular and allcause mortality in Western and Eastern Europe between 1970 and 2000. Eur Heart J 2006, 27:107-113.

2. Kuulasmaa K, Tunstall-Pedoe H, Dobson A, Fortmann S, Sans S, Tolonen H, Evans A, Ferrario M: Estimation of contribution of changes in classic risk factors to trends in coronary-event rates across the WHO MONICA Project populations. Lancet 2000, 355:675-687.

3. Björck L, Rosengren A, Bennett K, Lappas G, Capewell S: Modelling the decreasing coronary heart disease mortality in Sweden between 1986 and 2002. Eur Heart J 2009, 30:1046-1056.

4. Abildstrom SZ, Rasmussen S, Rosén M, Madsen M: Trends in incidence and case fatality rates of acute myocardial infarction in Denmark and Sweden. Heart 2003, 89:507-511.

5. Rosengren A, Spetz CL, Köster M, Hammar N, Alfredsson L, Rosén M: Sex differences in survival after myocardial infarction in Sweden; data from the Swedish National Acute Myocardial Infarction Register. Eur Heart J 2001, 22:314-322.

6. Gottlieb S, Harpaz D, Shotan A, Boyko V, Leor J, Cohen M, Mandelzweig L, Mazouz B, Stern S, Behar S: Sex differences in management and outcome after acute myocardial infarction in the $1990 \mathrm{~s}$ : a prospective observational community-based study. Circulation 2000, 102:2484-2490.

7. Koek H, de Bruin A, Gast F, Gevers E, Kardaun J, Reitsma J, Grobbee D, Bots M: Short-and long-term prognosis after acute myocardial infarction in men versus women. Am J Cardiol 2006, 98:993-999.

8. Kober L, Torp-Pedersen C, Ottesen M, Rasmussen S, Lessing M, Skagen K: Influence of gender on short-and long-term mortality after acute myocardial infarction. Am J Cardiol 1996, 77:1052-1056.

9. Abrahamsson P, Dellborg M, Rosengren A, Wilhelmsen L: Improved long term prognosis after myocardial infarction 1984-1991. Eur Heart J 1998, 19:1512-1517.

10. Moen E, Asher C, Miller D, Weaver W, White H, Califf R, Topol E: Long-term follow-up of gender-specific outcomes after thrombolytic therapy for acute myocardial infarction from the GUSTO-I trial. J Womens Health 1997, 6:285-293.

11. Maynard C, Every N, Martin J, Kudenchuk P, Weaver W: Association of gender and survival in patients with acute myocardial infarction. Arch Intern Med 1997, 157:1379-1384.

12. Langørgen J, Igland J, Vollset S, Averina M, Nordrehaug J, Tell G, Irgens L, Nygård O: Short-term and long-term case fatality in 11878 patients hospitalized with a first acute myocardial infarction, 1979-2001: the Western Norway cardiovascular registry. Eur I Cardiovasc Prev Rehab 2009, 16:621-627.

13. Goldberg R, McCormick D, Gurwitz J, Yarzebski J, Lessard D, Gore J: Agerelated trends in short-and long-term survival after acute myocardial infarction: a 20-year population-based perspective (1975-1995). Am J Cardiol 1998, 82:1311-1317.

14. Botkin N, Spencer F, Goldberg R, Lessard D, Yarzebski J, Gore J: Changing trends in the long-term prognosis of patients with acute myocardial infarction: a population-based perspective. Am Heart J 2006, 151:199-205

15. Maclntyre K, Stewart S, Capewell S, Chalmers J, Pell J, Boyd J, Finlayson A, Redpath A, Gilmour H, McMurray J: Gender and survival: a populationbased study of 201,114 men and women following a first acute myocardial infarction. J Am Coll Cardiol 2001, 38:729-735.

16. Lundblad D, Holmgren L, Jansson JH, Näslund U, Eliasson M: Gender differences in trends of acute myocardial infarction events: the Northern Sweden MONICA study 1985 - 2004. BMC CardiovasC Disord 2008, 8:17-27.

17. Ludvigsson J, Otterblad-Olausson P, Pettersson B, Ekbom A: The Swedish personal identity number: possibilities and pitfalls in healthcare and medical research. Eur J Epidemiol 2009, 24:659-667.

18. Wilhelmsen L, Rosengren A, Lappas G: Relative importance of improved hospital treatment and primary prevention. Results from 20 years of the Myocardial Infarction Register, Göteborg, Sweden. J Intern Med 1999, 245:185-191.

19. Eriksson M, Holmgren L, Janlert U, Jansson JH, Lundblad D, Stegmayr $B$, Söderberg S, Eliasson M: Large improvements in major cardiovascular risk factors in the population of Northern Sweden. The MONICA study 19862009. J Intern Med

20. Mahon N, McKenna C, Codd M, O'Rorke C, McCann H, Sugrue D: Gender differences in the management and outcome of acute myocardial infarction in unselected patients in the thrombolytic era. Am J Cardiol 2000, 85:921-926.

21. Vaccarino V, Parsons L, Every NR, Barron HV, Krumholz HM: Sex-Based differences in early mortality after myocardial infarction. $N$ Engl J Med 1997, 341:217-225.

22. Heer T, Schiele R, Schneider S, Gitt A, Wienbergen H, Gottwik M, Gieseler U, Voigtländer T, Hauptmann K, Wagner S: Gender differences in acute myocardial infarction in the era of reperfusion (the MITRA registry). Am 」 Cardiol 2002, 89:511-517.

23. De Gevigney G, Mosner S, Ecochard R, Rabilloud M, Cao D, Excoffier S, Cheneau E, Milon H, Delahaye F: Are women with acute myocardial infarction managed as well as men? Does it have consequences on inhospital mortality? Analysis of an unselected cohort of 801 women and 1,718 men. Acta Cardiol 2001, 56:169-179.

24. Perers E, Caidahl K, Herlitz J, Karlson B, Karlsson T, Hartford M: Treatment and short-term outcome in women and men with acute coronary syndromes. Int J Cardiol 2005, 103:120-127.

25. Boersma E, Maas A, Deckers J, Simoons M: Early thrombolytic treatment in acute myocardial infarction: reappraisal of the golden hour. Lancet 1996, 348:771-775.

26. Isaksson RM, Holmgren L, Lundblad D, Brulin C, Eliasson M: Time trends in symptoms and prehospital delay time in women vs. men with myocardial infarction over a 15-year period. The Northern Sweden MONICA Study. Eur J Cardiovasc Nurs 2008, 7:152-158.

\section{Pre-publication history}

The pre-publication history for this paper can be accessed here: http://www.biomedcentral.com/1471-2261/11/1/prepub

\section{doi:10.1186/1471-2261-11-1}

Cite this article as: Isaksson et al:: Better long-term survival in young and middle-aged women than in men after a first myocardial infarction between 1985 and 2006. an analysis of 8630 patients in the Northern Sweden MONICA Study. BMC Cardiovascular Disorders 2011 11:1. 